EGU21-679

https://doi.org/10.5194/egusphere-egu21-679

EGU General Assembly 2021

(c) Author(s) 2021. This work is distributed under

the Creative Commons Attribution 4.0 License.

\title{
How do transitions affect the wave overtopping flow locally as well as downstream?
}

\author{
Vera van Bergeijk, Jord Warmink, and Suzanne Hulscher \\ University of Twente, Marine and Fluvial Systems, Enschede, Netherlands (v.m.vanbergeijk@utwente.nl)
}

Wave overtopping on grass-covered dikes results in erosion of the dike cover. Once the dike cover is eroded, the core will be washed away and the dike breaches, leading to flooding of the hinterland. Transitions between grass covers and revetments or geometric transitions are vulnerable for cover erosion and are therefore the most likely locations to initiate dike breach. These transitions affect the overtopping flow and thereby the hydraulic load on the dike cover. For example, bed roughness differences can create additional turbulence and slope changes can result in the formation of a jet that increases the load at the jet impact location. Although it is known that dike cover failure often starts at transitions, the effect of transitions on the hydraulic load remains unknown.

We developed a detailed numerical 2DV model in OpenFOAM for the overtopping flow over the crest and the landward slope of a grass-covered dike. This model is used to study the effects of transitions on the overtopping flow variables including the flow velocity, shear stress, normal stress and pressure. Several types of transitions are studied such as revetment transitions, slope changes and height differences.

The results show that the shear stress, normal stress and pressure increase significantly at geometric transitions such as the transition from the crest to the slope and at the landward toe. The increase depends on the wave volume and the geometry of the dike such as the steepness and length of the landward slope. Furthermore, the results show that roughness changes at revetment transition on a grass-covered crest has no influence on the maximum shear stress, maximum normal stress and maximum pressure. The flow velocity increases from a rough to a smooth revetment, while the opposite occurs for the transition from a smooth to a rough revetment. The variation in the flow velocity is well described by analytical formulas for the maximum flow velocity along the dike profile. These formulas are also able to describe the variation in flow velocity for a revetment transition on a berm on the landward slope. In this case, the shear stress increases from a smooth to a rough revetment and decreases from a rough to a smooth revetment. This means that a rough revetment can locally reduce the shear stress, however the transitions have no effect on the shear stress downstream.

These model results are used to obtain relations for the increase in the hydraulic variables at transitions. These relations can be used to describe the effect of transitions on the hydraulic load in models for grass cover failure by overtopping waves. Accurate descriptions of the hydraulic load 
in these models will improve the failure assessment of grass-covered dikes with transitions. 